DOI: 10.2478/ausfm-2020-0002

\title{
Angry Old Men in Post-Crisis European Cinema
}

\author{
György Kalmár \\ University of Debrecen (Hungary) \\ E-mail: kalmar.gyorgy@arts.unideb.hu
}

\begin{abstract}
The paper explores the representation of ageing white men in $21^{\text {st }}$ century European art cinema in the socio-cultural context of the series of crises that European societies had to face in the first decades of the new millennium. In Europe ageing is a growing concern, which already influences economic productivity and further endangers the welfare system. Ageing white men, who used to belong to the hegemonic majority of society during their active period, are often disoriented and frustrated by rapid technological development, social changes, shifts in social values or the failures of the welfare system. This paper, through the analysis of Tyrannosaur (Paddy Considine, 2011), I, Daniel Blake (Ken Loach, 2016) and A Man Called Ove (Hannes Holm, 2015), explores the ways these issues are represented in contemporary European cinema. The films of this period often depict the disappearance of an old life-world, together with its old sense of community and its old types of men. Thus, these films tend to be critical of globalized modern societies, and often reveal both the vulnerability and the potential destructiveness of these vanishing masculinities. ${ }^{1}$
\end{abstract}

Keywords: masculinity, crisis, old age, white men, anger.

Old age has never been one of cinema's favourite topics. If such a sweeping generalization can be allowed, narrative cinema, historically, mostly favoured stories of young people, and, similarly to television, contributed to the systematic underrepresentation of elderly people in visual media (Harwood 2007, 151; Harwood and Anderson 2002; Chivers 2011, xv). Though in film history one finds numerous noteworthy examples of films telling stories about older people, in most cases old men and women play minor, supporting roles, a high percentage of which are fairly stereotypical, predictable stock characters. The silver screen seems to be no country for old men, and probably even less for old women.

1 This article was supported by the János Bolyai Research Grant of the Hungarian Academy of Sciences, and the Research Grant of the New National Excellency Programme (ÚNKP) of the Hungarian Ministry of Human Resources. The article is part of the forthcoming volume PostCrisis European Cinema: White Men in Off-Modern Landscapes (Palgrave-Macmillan, 2020). 
One possible reason for this may be that cinema, be that American or European, genre or auteur, heavily relies on the visual pleasures that the sights of young bodies entail. Ironically, oftentimes even films teaching (or preaching) the higher moral message that "what is essential is invisible to the eye" prefer to do so with actors and actresses who do look young and pleasing to the eye. The practical filmmaker's point seems to be that even if the film is to display the worst miseries and tragedies of life, it works better if there is something in the faces and bodies that visually attract, entertain or captivate the spectator. Though this tendency may very well be read as a sign of the irreducible frivolity of cinema, I would argue that there is more to this phenomenon than the simple addiction to voyeuristic pleasures, the secret affinity between pornography and cinema, or the sexual energies driving the cinematic narrative, as numerous psychoanalytic film theorists have been arguing since the seventies. It appears that there is something in the lack of youthful physical beauty that disturbs the entire sociocultural process of film-enjoyment and cinema-going, at least in its current form, which has been thoroughly intertwined with the cult of youth and beauty throughout its history (Chivers 2011, xv). The lack of youthful protagonists may disturb the cinematic processes of idealization, identification, affective suture, or generally the spectators' emotional connecting with the film, and this constitutes a risk that apparently most directors (and producers) simply would not take.

The other possible reason for cinema's inclination to tell stories of young people is that a narrative needs desire, action, drama and excitement, and people in their young age simply tend to have more of that. Besides cinema's much discussed patriarchal heritage and traditional connection with the perspective of active male protagonists, there is a number of sociocultural and probably also biological reasons why young men in particular tend to be in the centre of cinematic narratives. History tells us that it is mostly young men who make revolutions or fight in wars, criminality records tell us that they commit more crime and especially more of the violent and spectacular ones, insurance policies are based on the assumption that they are more likely to get into danger or take unnecessary risks. Young age in general means more filmic action, in terms of sex, romance, passion, violence or the will to take physical action in order to change the world, and it is probably through young, innocent eyes that the world's cruelty and corruption can be seen most clearly. Thus, both social and psychological statistics and the specific necessities of the film medium suggest that young people, and especially young men, tend to make much more visually interesting and actionoriented (and thus filmable) stories for cinema.

Beyond our "primate package" of behavioural heritage, as well as the above general cinematic considerations (which can be clearly traced back to the history offilm as such), 
one may also note broader cultural trends underpinning cinema's long-standing ageist inclinations. According to the literary gerontologist Kathleen Woodward, "in every culture, age, like any other important category, is organized hierarchically. In the West, youth is the valued term, the point of reference" $(1991,6)$, and "our culture as a whole has not succeeded in producing persuasive representations of aging - in particular of the aging body - which are characterized by tolerance" $(1991,8)$. Furthermore, one may notice a systematic disregard of old age in our culture (Woodward 1999, x), which, I would argue, may have something to do with how badly our modern, secular, individualistic culture handles issues of bodily decay, impermanence and death.

As a result, up until quite recently, old age as a central theme was mostly confined to well-defined quarters of the medium. Generally, one's impression is that old-age-related films were either farcical comedies, such as the Jack LemmonWalter Matthau Grumpy Old Men (Donald Petrie, 1993) and the British Waking Ned Divine (Kirk Jones, 1998), or contemplative, dark art-house films about death, impermanence and the meaninglessness of human existence, such as Bergman's Wild Strawberries (1957) or Kurosawa's Ikiru (1952) (see Chivers 2011, xvi-xvii).

As several film critics have noted, in the $21^{\text {st }}$ century one may notice a shift in this cinematic treatment of elderly people, and "the proportion and types of agefocused plots have increased" (Chivers 2011, xviii). Surprisingly, on both sides of the Atlantic, middle aged and old(er) people have infiltrated several genres previously explicitly associated with youth, such as action cinema or romantic comedy. As a telling example on this ever-widening palette, we even have a Pixar production about an old man, the remarkably sensitive and expressive Up (Pete Docter, 2009). Needless to say, there is no shortage of titles demonstrating the trend in European quality film either.

One can detect several causes behind the growing number of films about old people. The first is financial: as a result of ageing first world societies, and the shifting demography of cinema-going, film industry increasingly targets middle-aged and older audiences too. The second reason, arguably more relevant to European quality film, is that the series of crises characteristic of the early $21^{\text {st }}$ century has hit the elder population particularly hard. In the new millennium, there is plenty of drama about old age, and the cinematic representation of the troubles of the elderly is more and more of a must for any socially engaged filmmaker. Moreover, I would argue, the decreased sense of agency and increased insecurity of elder people make them apt representatives of the sorts of troubles many people go through in post-crisis Europe. The third, and most general reason is that when the overall demographic structure of the population is changing, the interpretation of different age groups 
inevitably shifts as well, which is bound to show in all fields of culture. One of the most exciting aspects of this cultural and cinematic transformation is narrative and stylistic: it would be logical to claim, as Sally Chivers does (2011, xvi), that older populations and older actors and actresses will require different narratives and perhaps different cinematic styles. And it is likely that audience demands will change what harsh critiques of the cult of beauty could not.

There are some specific trends to the socio-cultural context of this relatively new tendency in European cinema that one needs to address when examining films. The first is population ageing. As a result of longer life expectancy and decreasing birth rates, Europe's developed countries, similarly to those in North America and Asia, are going through a demographic transition never seen before in human history. Life expectancy has doubled since 1900, the number of people aged 60 and over has tripled globally since 1950, and researchers predict that in twenty years the largest population cohort in Europe will be those over 65. Though the increase in human longevity is to be applauded, the current demographic situation raises several concerns (Brinstock and George 2010).

The gradual dismantling of the welfare state, as many European citizens are all too painfully aware, has been well on the way before 2008. The main reason for this is that Europe's glamorous welfare systems were designed for very specific socioeconomic conditions, most importantly for the post-World War II booming economy and high birth rates (Kohli and Arza 2011, 252). Many contemporary pensioners grew up with this generous and caring model of the state in mind, and they had every reason to believe that after an early retirement they would be able to live comfortable, affluent lives. The system started to change in the mid-70s, when both economic growth and birth rates started to decline. By the 1990s, welfare costs were seen as explicit threats to economic competitiveness, benefits were cut and pension schemes rearranged in most European countries (Kohli and Arza 2011, 253-254). The long-term consequences of this history did not only concern financial policies and entailed the state's withdrawal from its former, caring responsibilities, but also led to a general decrease in social security and well-being, produced the precariat, the "new dangerous class," and rearranged family structures and gender roles too.

These social and economic rearrangements no doubt shaped the lives of many people in European societies, and seldom for the better. As several postcrisis European films also indicate, the way the state went back on its previous promises has left many with bitter feelings, weakened trust in public institutions, undermined the modern promise of endless progress, and often resulted in the cinematic production of bleak, off-modern landscapes. 
Of course, in this grim story white men still seem to fare better in most respects than either women or people of colour. Studies show that though age may make white men more vulnerable to such adverse social changes, they still enjoy certain privileges (Harrington Meyer and Parker 2011, 323). The tendency in developed countries is still that men work more than women, and usually in more responsible jobs (326), which means that old white men tend to be less economically fragile than women. Needless to say, more work and responsibility do not only entail certain economic safeguards, but also heightened stress and additional health risks, which may contribute to the fact that in developed countries men live about seven-yearshorter lives than women. As Frankenberg and Thomas point out, "men use and abuse alcohol and tobacco at greater rates than women, and men also face greater occupational exposure to hazards. Injury and suicide rates are higher for men than for women" $(2011,82)$. These statistics indicate the kind of strain times of crisis put on white male identities: at such times, lives and identities based on an older construction of masculinity that includes the breadwinner model, performance in the public sphere or financial productivity become particularly fragile and precarious.

\section{Tyrannosaur}

Few films express the bitterness, frustration and anger of elderly white men who have "eaten shit" better than Paddy Considine's directorial debut, Tyrannosaur (2011). The film tells the story of Joseph (Peter Mullan), a greying, working-class, alcoholic, unemployed widower with serious rage issues. It focuses on Joseph's friendship with Hannah (Olivia Colman), a middle-class charity shop worker, as well as Samuel (Samuel Bottomley), a six-year-old neglected boy living opposite the street. The narrative focuses on how the dramatic events around him, most importantly the abuse suffered by Hannah and Samuel, help Joseph channel his inner turmoil towards legitimate goals, and turn him into some sort of a lonely, silent, involuntary protector.

This summary should not deceive anyone: Tyrannosaur is not a sentimental journey of two battered people finding redemption and true love in each other's arms, nor is it a story of a lost soul who finds his true self and becomes a saviour. Though reckoning and redemption are among its key motifs, Tyrannosaur follows the tradition of British kitchen-sink dramas and gritty social realism, and never shies away from facing the darker, deeply compromised, destructive aspects of its main characters, or the profound disillusionment that almost all the characters share. 
Joseph has "eaten shit" and in his world, "it’s dog altogether" - as Tommy, Joseph's drinking buddy succinctly puts it. The film's reliance on authentic locations in Leeds, its interest in the nitty-gritty life of the lower classes, its refusal of middleclass decency (and hypocrisy), its angry critique of the dog world that (some parts of) Britain has become connect it with a long-standing British tradition in literature, theatre and film that involve the 1950's Angry Young Men movement, as well as the work of such socially committed filmmakers as Tony Richardson, Mike Leigh, Ken Loach or Shane Meadows. With its strong intertextual ties and cinematic references, Tryannosaur creates a historical arch stretching between the angry young men of the fifties and the angry old men of the early $21^{\text {st }}$ century.

The first, introductory scene already lays out everything that can go wrong or become toxic about white masculinity. Joseph gets drunk and upset about the bookies, and when he is thrown out, in his rage he kicks his poor dog's ribs in. In the first two minutes of the film Joseph displays everything that makes one keep away from such men: cursing, verbal abuse, violence, destructiveness, drinking, gambling, and taking out anger on weaker ones. Yet, the film does not stop here: it also shows the ensuing remorse and bitterness, the moment of clarity when the cloud of rage has passed, as well as the painful recognition of one's own destructiveness. Joseph carries Bluey home, through the shabby post-industrial outskirts of Leeds, and buries him in his yard. Rage and reckoning, violence and remorse, aggression and small gestures of kindness constitute the emotional roller coaster the film follows. Tyrannosaur, undoubtedly partly because of Mullan's superb performance, manages to take us inside the world of someone that we usually avoid for very good reasons, and thus provides a psychologically accurate, yet compassionate picture of an all too well-known sort of violent white masculinity.

The film presents rage as a result of an intimate part of a certain culture of disillusioned, frustrated masculinity, a desperate and distorted expression of human agency and dignity in situations where one is denied any sense of agency (Bradshaw $2011,1)$. The film can be seen as a study of the anger issues of disenfranchised men, the relationship between socio-economic deprivation and anti-social behaviour, or generally of masculinity gone monstrously wrong. After all, most characters are men, and all of them in important roles are terrible people. It is quite telling that there are only two or three women and one child in the film, and all of them are victims of male domestic violence.

However, in spite of the above general ramifications, Joseph's is not a universal, textbook-like psychopathology: it is built from and coloured by hundreds of cultural markers. Race, class, gender, the history of the British working class, the 
post-industrial landscapes of the Midlands, the usual furniture of the unpretentious British corner pub, the sight of a pint on the table in front of a solitary white man, the grey metal shutters on shop windows in the lower part of town all provide the characters with subtle details, historicity, geographical specificity, and the feeling of authenticity. With the strict segregation of the upper and lower classes into the upper and lower part of the town, the film clearly connects to the world of contemporary globalized capitalism, where those who cannot adapt to the quickly changing circumstances are simply left behind. Hannah's infertility, and the general scarcity of young people in the film explicitly relate to the above discussed demographic issues, and add a lot to the gloomy, slightly end-of-the-wold atmosphere that creeps into the film's otherwise fairly strict realism.

Joseph's charity shop encounters with Hannah are among the scenes when these nuances are laid out. It is after a pub fight that Joseph seeks refuge in the charity shop for the first time, though it is unclear whether he wishes to flee from the revenge of the youngsters whom he has attacked, or rather it is his own bad conscience that makes him hide behind a rail full of used women's clothing. Hannah tries to help, offers even to pray for him, yet Joseph seems beyond redemption. Though he silently cries behind the clothes, the next day he rebuffs Hannah's religiouslytermed help as fake and condescending: “God ain’t my fucking Daddy. My daddy was a cunt, but he knew he was a cunt. God still thinks he is God. Nobody told him otherwise. [...] I met people like you in all my fucking life. Goodie goodies. Make a charity record. Bake a cake! Save a fucking soul! You've never eaten shit. You don’t know what it's like out there. You haven't a fucking clue!”

The rejection of the "goodie-goodies" turns into explicit scorn when it turns out that Hannah lives in Manors Estate, a posh, middle-class part of town up the hill: "Manors fucking Estate! How is Manors Estate? How are the five-bedroomed, double-garaged, nicely trimmed lawn, fondue, coffee-morning fucking lifestyle Manors Estate? How is it up there? Swimming, is it? What the fuck are you doing down here, huh?" These monologues, I would argue, are significant because here it is not only Joseph who is rejecting the sweet narrative of soul-saving as a condescending, dishonest, middle class fairy-tale. Though he apologizes to Hannah the next day, this seems to be a position that the film as a whole shares. It can be read as a statement about Tyrannosaur's possible interpretations: it warns us never to understand Joseph by the end of the film simply as a redeemed, righteous man, now walking the straight and narrow path. This is not a film with an unambiguous happy ending or an uplifting moral message, and by the end, the well-meaning middleclass spectator will not be able to lie back with the comforting feeling that after all, 
all people are essentially good, and everything is OK with the world. Joseph's nasty words warn us against pretending that we completely understand him, that we can fully integrate him into a nice cosy world of meaning, our meaning.

This is a film about wasted lives, and its general approach is less that of redemption than mourning. Nowhere does this become clearer than at the funeral of Joseph's best buddie. The connection between masculinity and death runs deep in our mythologies of gender, and will be fully played out in the other two films discussed below. However, in Tyrannosaur it is not Joseph who dies, but his old drinking mate, who also stands for the nasty part of Joseph's character. There is only one conversation between the two men before the friend dies, which can be seen as a twisted version of the above quoted one where Hannah tried to convince Joseph that God loves him. Here, once again, we witness the rejection of idealizing and consoling "goodie-goodie" narratives: at this time it is his dying friend that insists that he is "fucked," that his daughter hates him and he is going to hell, and it is Joseph who tries (probably unsuccessfully) to convince him otherwise.

The friend's funeral, as well as the farewell party in the local pub are key scenes for the film's take on these kinds of masculinities. Both Joseph and his friend were abusive husbands, and in their old days both look back on that with regret. To make the scene even more ambiguous, Hannah who has just been beaten up by her husband, parties with them, and finds refuge with them. These ambiguities are never resolved in the film: the party makes it clear that the dead friend was both loved and hated by his daughter. Similarly, when later Hannah asks Joseph whether he loved his wife he says he loved her and hated her. Because of this emotional ambiguity there is no nostalgia associated with mourning and melancholia here. When Hannah asks whether Joseph would like Pauline, his deceased wife to be alive and here with him, he clearly says no, which expresses the film's general attitude to the past. We see old types of men dying, the old shed torn down, an old world and old culture of masculinity going by, things that the film both loves and hates, and Tyrannosaur manages to make us mourn these without wanting to bring them back.

The most expressive image of this attitude is that of Joseph sitting in his old armchair, in the middle of his side-yard, amidst the ruins of the shed that he had recently torn down. [Fig. 1.] He is wearing his usual black trousers and a (once) white undershirt, the kind that is often called in Britain sarcastically a "wife-beater." In his right hand there is a machete, in his lap the head of the neighbour's Pitt-bull that attacked the boy Sam. He is a terrible but spectacular sight, an old patriarch, whose kingdom has been reduced to a run-down side-yard and a torn-down shed, which he destroyed himself because it connected to too many bad memories. He sits there 
as a tyrant, a mad king of a terrible bygone kingdom, yet with a sense of justice. This time, the killing of a dog was for the protection of innocence, and Joseph was the only one who decided to do something to end the abuses that Sam had to suffer from his stepfather and his fighting dog.

Thus, the two dog-kills map Joseph's inner journey: from killing his only friend in a momentary outburst of rage, to a bloody but premeditated act of protecting innocence in a dog-eat-dog world. With this act, the film also criticizes our all-toodecent ways of turning our heads when seeing injustice, and suggests that perhaps we still need men who are capable of taking action. Joseph may be an old type of man, who has to go, yet the film also subtly calls one's attention to the uncomfortable question where we will be, how we will deal with such issues without people like Joseph taking action in such situations.

One of the telling details and possible strengths of the film is that Joseph's rage against the world is never given a direct cause. There is no original trauma (that we, well-meaning, educated spectators of art films so much like to have), we see no past event outside his power that made him a villain, something that would help us see him more like a victim. He knows and explicitly states that he is not a nice person, and the film wants us spectators to accept that, to see him without categorizing him either as a villain, a victim or a saviour of the weak. He is simply like that, a man struggling with his own bitterness, anger and rage. His rage is somewhat like his old friend's cancer: a part of him that he can neither control nor understand. An illness that both he and the ones around him are suffering from, yet something that - to a large extent - defines him.

This lack of psychological motivation makes the film and its critical edge immensely stronger. The way Joseph's above quoted monologue pulls him out from under God's providence, this lack of psychological understanding pulls him out from any universal humanist interpretation. This way the film retains a segment of meaning that cannot be translated into words and concepts, something weighty, perhaps even traumatic, that we cannot explain away. He is an Other, also to himself, a symptom, a malfunction, a painful mistake with a consciousness and an ability to suffer. An otherness that challenges our world, while indicating our potential responsibility. Joseph remains intimately close, yet out of arm's reach: we cannot save him, only mourn him. 


\section{I, Daniel Blake}

Ken Loach's 2016 directorial comeback, I, Daniel Blake is probably the most wellknown of the three films I discuss in this paper. It was reviewed in most major European newspapers, won the Palme d'Or in Cannes as well as a BAFTA prize for best British film. Though it tells a fairly simple, straightforward story of an ordinary man falling through the cracks of the social security system, it clearly pictures larger social processes, and taps into some of the most pressing issues of our time.

I, Daniel Blake is Loach's “angriest film” (Hattenstone 1), "a battle cry for the dispossessed" - as Mark Kermode called it in the Guardian. It recounts a few weeks in the life of Dan, a widowed carpenter in Newcastle, of about sixty years of age. After a near-fatal heart attack, his doctors tell him that he cannot go back to work, yet the health-care professional of the American company to which the government has outsourced benefit allowance evaluation deems him fit and thus not entitled to sickness benefit. Thus, he gets trapped in a series of catch-22 situations, yet another victim of the bureaucratic machine of the contemporary British welfare system. The narrative, which spans between two heart attacks, recounts his struggles with an inhuman system that was not designed for help, his growing frustration and anger, as well as his desperate attempts at preserving human dignity. As in Tyrannosaur, a female friend becomes a key element in the plot: this time it is Katie, an unemployed single mother with two small kids, who had to move to Newcastle from London because available council accommodation can only be found there. Unlike Joseph, Dan is basically a nice old chap from the very beginning. The old sort of patriarchy that he represents does not include violence or (self-)destructive attitudes, but rather such traditional working-class values as a dignified work ethic, honesty, solidarity, and a simple, matter-of-course helpfulness towards the ones around him. True to Loach, the film was shot on real locations in Newcastle, the social and institutional background is well-researched, the traps of the system are real. As usual in this type of British realist filmmaking, the cinematography is unaffected, documentary-style, avoiding sensationalism, relying on the sheer force of human drama conveyed by great acting. As in Tyrannosaur, the raw power of the unfolding events, real places and the use of basic cinematic techniques add to the feeling of authenticity and only make the cinematic experience stronger.

Loach has been the voice of the silenced and dispossessed all through his career. His socially engaged, politically charged works managed to call public attention to social injustices time and time again. The awareness about single mother and child homelessness raised by his BBC television play Cathy Come Home (1966) 
led to a parliamentary discussion of the issue, but his films also motivated the establishing of several charity organizations. Loach's international reception tells a lot about how the crisis has changed our perceptions: while his earlier works met mixed international critical responses, were often criticized as politically biased and didactic, and were even censored and banned in the 80s, his post-crisis works are received in a markedly different manner. Perhaps the ageing director's political message has also become more subtle, but it is also quite likely that Loach has been making more or less the same points all through his life, and it is simply the recent crisis that makes his work less "didactic" and more realistic. Arguably, the economic crisis and the general sense of resentment about where neoliberalist policies led us make his works quintessential expressions of the spirit of our times. I, Daniel Blake is not only about a simple guy in Newcastle, or the controversies around the British social security system. The film came to cinemas in late 2016, in the year of the Brexit vote, and it dives into some of the very social processes that are currently tearing Europe to pieces. I would argue that the film reveals some of the causes of the resentment, frustration and anger about the brave new world of neoliberal capitalism that motivated so many angry protest voters, and ultimately led to Britain's leaving the EU. On an even more general level, the film also investigates crucial questions concerning identity in the $21^{\text {st }}$ century, such as what happens to a work-based, breadwinner masculine identity when ageing or health issues knock on the door, or when the global economy simply finds somebody redundant.

The film's fist scene, half of which is just a dialogue we hear while watching credits in small, minimalist white letters against a black background, manages to set the main theme and atmosphere of the film as much as the first scene of Tyrannosaur did. Here we listen to the dialogue between Dan and the healthcare professional (who turns out to be neither a doctor nor a nurse). It quickly shows that the questions asked (such as "Can you walk fifty meters without assisted by any other person" or "Can you raise either arm to the top of your head?") do not have much to do with Dan's heart condition, which he tries to explain, but to no avail. Clearly, the healthcare professional's goal is not to understand his particular condition, or to find the best solution to his case, but just to go through the form and tick yes or no after each question. Annoyingly enough, she asks each and every question with the same intonation, sounding almost like a robot. (As a matter of fact, many virtual assistants that operate at the other end of the line at big companies at the time of writing fare better at meaningful intonation.)

It is no coincidence that the healthcare professional's face is never shown in the film: she is the first representative of a faceless, inhuman system that Dan meets. 
As it turns out, it does not make much difference whether he is talking to real life human beings (at the Jobcentre Plus, for example), or to the answering machines of various institutions that keep him waiting for hours, or someone at a call centre: everywhere he meets the same lack of competence, as well as the lack of useful information, practical help, or will to solve his case. This is not a Terminator-movie, or a Matrix type of dystopia, no secretly self-developed artificial superintelligence has sneaked out from Google to finish off organic life-forms on the planet, yet one gets the impression that an inhuman System has taken over this segment of society, and ordinary human beings hardly stand a chance.

Of course, the phenomena of self-serving inhuman bureaucratic systems or male resistance to them are not new at all, as every reader of Kafka's The Trial or Melville's Bartleby knows. There is a long and well-documented history of male disaffection and discontent in the face of the ever more sophisticated and more bureaucratic systems of first world societies. As Robert T. Schultz contends in the context of American literature and film in Soured on the System, "in various late nineteenthand twentieth-century cultural texts men's agency is depicted as being on the decline, and that decline is associated predominantly with the reorganization of social and economic life that accompanied the corporate reconstruction of [...] capitalism" (Shultz 2012, 7). I, Daniel Blake, together with Kafka, Melville and countless other similar examples may lead one to a key recognition regarding the issue of agency and modernity. Let us recall that Foucault in Discipline and Punish discussed the post-eighteenth century shifts in the working of power, most importantly the shift from direct physical punishment to inner discipline, in a somewhat celebratory tone, as one of the necessary conditions of the birth of Europe's first sophisticated modern societies (see for example, Foucault 1977, 202-203). These films and pieces of literature, however, also attest to the drawbacks of these cultural paradigm-shifts. Discipline, internalized power, bureaucratization and institutionalization have surely made human life more civilized, and freer from physical violence. Yet, as these new agents of power are much harder to spot, resist, target and fight, this shift also led to a decline in one's sense of agency. It is a telling detail, in this respect, that the most important blind spot of Foucault's theories is that of resistance and human agency (see Certeau 1984). As several post-crisis social surveys and health statistics indicate, this may have more damaging effects on men, whose gendered identities are arguably still more reliant on activity in the public sphere.

Moreover, as most of us know from experience, modern technology took bureaucracy's frustrating effects to a new and unnerving level: after all, only machines can repeat the same sentence or the same five minutes from Vivaldi's The 
Four Seasons exactly the same way for an infinite number of times. Unfortunately, this is not just a small, annoying aspect of $21^{\text {st }}$-century life, a small bump on the glorious road to utopia: for those whose livelihoods depend on getting things sorted out as fast as possible, such bureaucratic traps are hell, a gradual descent into desperation and humiliation. First, because when you talk to machines or machineminded bureaucrats, you are reduced to something subhuman: numbers, codes, points, a set of possible and well-identifiable pre-coded answers, ones and zeros, yeses and nos. Second, as the film shows in psychologically precise ways, because fighting such an invisible, all-pervading system gradually deprives one of all sense of human dignity and agency. Thus, one of the questions that the film asks is what happens to human beings, and more specifically with honest, hard-working men who have built their lives around work, production and activity, when they are deprived of all these. The disheartening answer here is that in $21^{\text {st }}$-century Europe these men have little chance to enjoy any of the respect that they did either in traditional societies or during more affluent times of industrial modernity.

"They'll fuck you around," the next-door black lad tells Daniel, "make it as miserable as possible - that's the plan." And indeed, time after time, Dan finds himself facing problems that were actually generated by the system. All through the film, he tries to reason, to point out the obvious solutions, as one would do in any normal human interaction, but no one can or would listen to him. Of course, when one's sense of agency is taken away, frustration, resentment and anger follow. When you realize that you have no chance to make yourself heard, when you understand that the system is not for, but against you, and you cannot mend it - then you go into protest mode, as Dan does, or just try to break the system any way you can, as arguably many Brexiters (and Trump voters) did.

Interestingly, in the film it is Katie's small son, Dylan who best expresses this dynamics of frustration. One day, while Dan is helping the family, mending this, fixing that in the house, Dylan keeps bouncing his ball hard and loud on the stairs, without end, in quite a nerve-wrecking manner. Dan tries to start a conversation, or get him help him, but nothing works: he would not answer questions, and would not stop. Seeing Dan's bewilderment at the situation, Daisy, the older sister explains: "He does it when he's angry. People never listen to him, so why should he listen to them?" This scene adds two things essential to the meaning of the film. First, it shows the above-mentioned dynamics of frustration and destructiveness: Dylan had to leave his friends and relatives in London because of a system larger than him, which he had no chance to argue with. This frustration leads to anger, which is expressed in destructive protest action the only meaning of which is its 
meaninglessness. Second, the scene associates such acts of protest, including Dan's later graffiti-vandalism (and possible protest votes), with the innocence of a child. The scene suggests that angry protest in such situations is legitimate, and it results from the frustrating lack of power and self-determination, rather than malice or the taste for destruction.

Details of Dan's life enrich his fight with the system with further and less political resonances. He is a carpenter who has been working on construction sites all his life, and his hobby is carving all sorts of artefacts from wood. This is a symbolic choice for a number of reasons. Dan's craftsmanship associates him with the old economy of material production, where people still produced something material and practical, something you can see, grasp and appreciate (as opposed to most office jobs offered by corporate capitalism, where you work at what Marc Augé has called non-places, never leave your computer, and never really see the physical results of your work). I would argue that there is much more at stake here than the demise of the traditional working class, or the crisis of work-oriented breadwinner masculinities. The film also comments on the rapid technological change that has reorganized our societies to an unprecedented degree in the past few decades, the change that makes human life more and more devoid of sensory affect, real objects, organic surroundings, and meaningful, face-to-face human interaction. The world of globalized capitalism in the digital age looks more and more like a giant simulation, designed and run by a narrow and well-paid elite of technocrats (and their algorithms), where people like Dan appear like obsolete organic leftovers. This world is "digital by default," as Dan is informed at Jobcentre Plus, which is a completely unknown world for an elderly carpenter, who is, as he remarks, "pencil by default." One wonders to what extent the elderly's distrust and fear of this new, technocratic world played a part in the Brexit referendum: after all, the greatest of such faceless, technocratic, digitalby-default bureaucratic institutions is the EU itself. The position of I, Daniel Blake is clear on this. The only valuable help Dan gets during his crisis is coming from people outside these bureaucratic institutions: neighbours, friends, co-workers, that is, ordinary people still operating on basis of an old kind of humanity and social solidarity. The only person at Jobcentre Plus who does help Dan does it by going against protocols, and gets duly reprimanded for it. Thus, I would argue that what the film presents us, perhaps against Loach's intentions, is not simply a contrast and conflict between the inhuman institutions run by the neoliberal state on the one hand, and ordinary human beings following an old-school community spirit on the other. It is also a contrast and conflict between the new and the old, digital and organic, numbers and affective qualities, bureaucratic responses and genuine 
human interactions, machines and humans - which may very well be one of the defining set of conflicts of $21^{\text {st }}$-century life.

At this point, let me refer briefly to Thomas Friedman's book Thank You for Being Late: An Optimist's Guide to Thriving in the Age of Accelerations, which was similarly published in 2016. Friedman makes at least two points that are significant for the context of the film. First, he demonstrates that changes in the most formative aspects of our life conditions have been accelerating exponentially in the last few decades, with a speed that is simply incompatible with the adaptive potential of biologically and psychologically defined human beings. In other words, the technologically-driven transformation of modern economies, labour markets, natural habitats or communication patterns can be disorienting and frightening (especially for older and digitally illiterate people) partly because of the sheer speed of change (Friedman 2016). In the context of the present paper it is particularly relevant to notice that the fastest transformation of the world during human history takes place in front of the eyes of the oldest (and therefore possibly least flexible) population that has ever lived on the planet.

The second point Friedman makes that is worth considering in the context of the social processes that the film taps in, is that such historical events as the Brexit referendum or the 2016 US elections (where Donald Trump was elected president) can be seen as signs of a backlash in the developed world against these frightening accelerations. In other words, the conflict between ordinary human beings left behind by the system and the new, quickly developing technocratic world that $I$, Daniel Blake presents, is also a conflict that determined the outcome of arguably the two most important votes with symbolic value in the $21^{\text {st }}$ century so far, the Brexit and Trump's presidency.

Dan's journey is that of defeat and withdrawal: from work to his home, from the world of digitalized bureaucracy to such an old-school, real-life mode of public protest as writing graffiti on the wall of a public institution, from attempts at coping with the system to stubborn defiance. The public celebration by passers-by that accompanies his street protest clearly pits the local community of ordinary citizens against the representatives of the inhuman system. The scene, as many others, expresses anti-neoliberal, anti-modern, anti-globalization sentiments and can be clearly read as a pledge for an old sense of justice, dignity and solidarity. I, Daniel Blake, however, remains realistic about the practical fruitfulness of such public demonstrations. Though the protest is an empowering ritual in which both Dan and the spectator learn with relief that there is a community that can stand together, the ensuing celebration cannot last long. Dan is taken away by the police, and his act 
remains an angry, spectacular, but ultimately futile gesture. As in Tyrannosaur, such actions, motivated by frustration and anger, are the last and only means through which agency and human dignity can be expressed, also the only acts through which masculinity is connected with power and activity in the public sphere. Importantly for the film's overall picture of contemporary social issues, these defiant gestures remain mostly symbolic, seldom solve anything, and tend to bring trouble to the desperate men resorting to them [Figs. 2-3].

The film is clearly pessimistic about the chances of these old (kind of) men to enter the $21^{\text {st }}$-century life-world or meet its challenges. Dan's death can be regarded as symbolic in this respect. Even though a lawyer that his friend Katie got him promises success, he never lives to see it. Thus, his funeral, the film's last scene, becomes a mourning of more than one man. Similarly to Tyrannosaur's last shot, which shows Joseph walking away from the camera in a symmetrical composition, this is a symbolic good-bye: there is the sense of a farewell to an old kind of man that simply has no place in our rapidly-changing world. The difference is, however, that Dan's life was not wasted, like that of Joseph: there is no history of violence here, but rather a history of caring and help. Though Dan upholds an old sense of order in an older style of patriarchy that younger generations may dislike (he reminds his young neighbour to take away his smelly garbage from their shared corridor, he shouts and curses at the man who repeatedly takes his dog to shit in their yard), he never becomes violent or physically threatening, and relates to people in need with a spontaneous, down-to-earth, unsentimental helpfulness. Moreover, he has a whole set of traditionally feminine characteristics: we learn that he used to take care of his sick wife for years before she died, and he is happy to look after Katie's children while she is out looking for work. Thus, he has to seek no redemption. Quite the contrary, with Dan's death, the film mourns the loss of and pays homage to an old type of man and the values he lived by.

\section{A Man Called Ove}

The Swedish A Man Called Ove (En man som heter Ove, Hannes Holm, 2015) presents a markedly different take on the issue of ageing white men in Europe's rapidly changing $21^{\text {st }}$-century societies. Though the number of motifs shared with the previously discussed films is conspicuously large, the approach, the style and the emotional journeys are quite different. In this adaptation of Fredrick Backman's best-selling novel, similarly to the previously discussed films, one finds a working class widower, out of work, going through a period of personal crisis, struggling with 
alienation, loneliness, lack of purpose, and absence of meaningful human relations. And as in the previous films, it is through finding new human relationships, face to face "neighbourly" connections (and the responsibilities that come with them) that the existential crisis is abated, and some sort of purpose or meaningfulness is found by the end of the narrative.

In spite of all these similarities, Ove offers a completely different experience for the viewer: this time it is not gritty social realism set in Broken Britain, but a hyperrealist black comedy placed in a neat and well-kept Scandinavian gated community. Moreover, here drama is regularly sweetened by touches of nostalgia and sentimentality, and slightly complicated by irony, black humour and selfreflexive distancing. As opposed to the straightforward heart-gripping-stomachpunching emotional rollercoaster of the first two films, here one generally encounters a feel-good approach with heart-warming moments, and a delicate balance between nostalgic sentimentality and instances of that particular kind of dark Nordic humour that non-Scandinavian spectators either instinctively get (and thus enjoy) or simply do not (in which case the film is practically unenjoyable). The immediate Nordic intertext of Ove would include the adventure-comedy The Hundred Year Old Man who Climbed out the Window and Disappeared (Felix Herngren, 2013) and the comedy-drama Elling (Petter Naess, 2001). As the generic tags also indicate, these also combine the theme of men in crisis with (weird and often dark) humour, as well as surrealistic or hyperrealistic storytelling. Regarding the wider context of Ove, Bergman's Wild Strawberries must also be mentioned, arguably a paradigm-setting art-house film about ageing. While The Hundred Year Old Man and Elling share Ove's fondness of absurd, dark humour in their approach to ageing, isolated men, Wild Strawberries is a significant precursor with regard rather to its fundamental situation of an embittered, cold, slightly sociopathic man re-evaluating his life before death.

Similarly to the other two films discussed above, Ove starts with a short prelude before the main title that serves as an introduction of the main character, as well as an outline of the key social and psychological issues that define ageing and masculinity in early $21^{\text {st }}$-century Sweden. In the very first shot we see an elderly man looking at bunches of flowers in a gardening store, where - as the spectator immediately understands - if you have a coupon, you can buy one bunch of roses for 50 krones and two for 70 . The next shot shows the man at the counter, trying to buy one bunch for 35 , quarrelling indignantly with the shop assistant, who is patiently trying to explain to him the logic of the deal. Next, we see him at a railway crossing in front of a cemetery, with the flowers in his hand [Fig. 4]. At this cut, the change of sound marks the change of mood: the smooth shopping music from the 
store is suddenly interchanged by the harsh noise of the train passing by, then by the silence of the cemetery, and Ove's clumsy words as he is trying to explain the flower incident to his deceased wife. "That's all wrong! That's totally insane!" - he says, which we will soon understand as his general opinion of the world around him. He arranges the flowers, cleans the top of the gravestone with a handkerchief, pauses for a moment and says "Miss you."

These scenes define Ove as the stereotypical cantankerous old grump that everybody avoids, and thus sets the scene for the comic parts to come. However, as some of the above details may have indicated, this prelude also starts building up the emotional history that led to Ove's embitterment. Arguably, it is this retrospective psychological inquiry that makes the film more than just another absurdist black comedy about a grumpy old man: this is what turns the film into an in-depth study of the recent history of Europe and its ageing men.

Similarly to the other two films, the prelude shows the main character getting upset over something ordinary, and thus associates ageing men with frustration, anger, and harsh criticism of the current state of the world. This seems to be a logic very similar to the meaningfully marginal perspectives created by old age in general in the Wild Strawberries cinematic paradigm. As the nearness of death may create a perspective from which life can be seen and evaluated as a whole, social and emotional marginalization may create a perspective from which our current social systems can be critically assessed. In both cases it is exclusion from the centre (or the mainstream) and regarding phenomena from the margins that produces meaningful insights, it is hard to notice when one is still successful and/or in the middle of life. Ove's most direct critique in this opening scene concerns consumer capitalism, although (in line with the absurd humour and constant distancing) it is clear that he is neither right about the specific issue (the flower deal), nor has any chance of winning his case, which is clearly indicated by the fact that in the cemetery we see him with two bunches of flowers.

The film's real narrative, however, starts only a couple of minutes later, with Ove's loss of his job at the railway wagon factory. Having done his early morning routine social-work-and-security-round-trip at the gated community (collecting cigarette stubs, checking that garage doors are properly closed, double-checking that recycled garbage is properly selected, making notes of improperly parked cars, cleaning kids' toys left buried in the sandbox, chasing suspicious-looking cats away from the sandbox), Ove goes to work in his old Saab. As a symbolic signifier of the marginality or anachronistic quality of his blue-collar job (or the Swedish heavy industry in general), a static aerial shot shows his blue car turn left at a roundabout 
where all the other cars go straight. In the factory (where Ove is in a blue overall, among blue machines, inspecting railway wheels with his papers in hand), he is called into the office by two managers, men half his age in white shirts and suits. In the office the managers, who are sitting at a desk with their identical laptops open in front of them, fire Ove according to the rhetorical and ethical standards of contemporary corporate capitalism. With forced, wry smiles they break the news to Ove that after 43 years of work at the company, and even though he is only 59, they thought that he would fancy doing something different, and therefore offer him a government-paid education course in digital literacy. As a clear commentary on the concerning social issues (also seen in I, Daniel Blake), in this scene the white-collar/blue-collar difference on the two sides of the desk is coupled with the antagonism between young and old, winner and loser (of global capitalism), as well as that of digital and analogue (laptop versus pen and paper).

Ove, of course, immediately understands that he is being fired, even if in this cultural environment nobody would call a spade a spade, and thus simply walks out the door. When he is about to leave the office, however, so as to make the farcical situation even more pointed, the managers stop him to offer the company's farewell gift, a spade "for gardening." It is a telling detail that the gift is picked up from a long line of spades placed by the wall behind them, suggesting that many of Ove's colleagues will soon get the same generous offer. The real critical edge of the scene, as well as the source of Ove's humiliation, however, stems from the twist in the power/ age relations: in this scene, seniority is associated with disempowerment, lack of competence, as well as economic and social redundancy. To make things worse, the managers keep using euphemisms and sweet lies to cover up the moral susceptibility of their decision to fire someone after 43 years of "loyal service" (as Ove calls it), thus associating the new generation and the new (global, neoliberal, corporate) capitalism with hypocrisy, inauthenticity and the lack of human responsibility.

So far, A Man Called Ove hardly presents anything really new: similar situations of men mistreated by corporate capitalism abound, moreover, in Ken Loach's The Navigators (2001) one finds this well-known drama (of the decline of the working class, of privatization and outsourcing, men's economic redundancy, short-term contracts and precarious existences) in the similar setting of a British railway company. What makes Ove unique in this cinematic context is what comes after this almost caricature-like commonplace scene. As he has nothing more to live for, he decides to end his life, and the rest of the film is structured by his repeatedly failed suicide attempts. However, each time he tries to commit suicide, some silly, ordinary event ruins his plan. Furthermore, each near-death experience brings up 
memories and visions of the past. Thus, with each suicide attempt the spectator gets a glimpse into Ove's past, into the beautiful and the tragic events that led to his present miserable existence. Significantly for the aesthetic qualities of the film, each (often nostalgic) recollection ends with some kind of darkly humorous event forcefully dragging Ove back to life. With this twist, the film manages to evoke a saturated, nostalgic view of the personal and national past, contrast past and present, yet to do it in a way that avoids uncritical sentimentality.

These absurdly funny situations often include a family of new residents moving next door. As it is a young family (regarding their age, the parents could be Ove's children) with two little girls (while Ove and his late wife did not have any children), and the wife is of Persian origin, their interactions set in motion an intricate dynamics of social and political relations, as well as thematize several hot contemporary issues. It is their arrival, more precisely the husband's clumsy manoeuvring with the semitrailer in front of Ove's window, which first makes the control-freak Ove get the rope off his neck and climb down from the chair so as to get the trailer in position without any further bumps on the nearby fences or post-boxes.

The fact that it is this new, young family that accidentally but repeatedly hijacks Ove's suicide attempts highlights the way the film twists the commonplace relationship of past and present, old and new. Whenever Ove is about to submerge in his nostalgic near-death visions about his past (hanging from the noose or inhaling his car's emissions in the closed garage), these annoying but sympathetic newcomers always draw him back into life, inadvertently and gradually endowing his life with new tasks, responsibilities, and even new purpose. In their relationship Ove clearly represents an old kind of masculinity, an old sense of order and way of life. In many ways, Ove's character functions in the film as a connection between past and present, a reminder of the passing of time and all the valuable things being lost. Thus, in this film, the past is not simply obsolete and irritating, but it is also something worth mourning.

The passing of time, loss and mourning are key issues in both Ove's character and the film's approach to recent history. As the spectator learns, before losing his job, Ove lost his mother at an early age, he saw his father hit by a train at the wagon factory on the day of his graduation, he witnessed their old house burning down (probably deliberately set on fire by the "white-shirt" investors who wanted to build a gated community on the land), lost their unborn baby when he and Sonja suffered an accident during a vacation, and finally saw his wife Sonja die in cancer as well. He still wears his father's watch, which he got on the day his father died, a detail that clearly indicates that he lives in the past, according to old standards and ideals. In his house not only the young Sonja's picture is displayed, but her clothes are still 
hanging in the closet. These details suggest that Ove's mourning processes have been stuck, and the series of losses that he suffered simply do not let him move on.

Though the long list of Ove's losses is something that (hopefully) very few people share, the above motif of accumulated unprocessed traumas can be recognized as a characteristically $21^{\text {st }}$-century socio-psychological phenomenon. As already mentioned in the previous section in connection with Daniel Blake's problems with the "digital by default" system he struggles with, due to the ever more accelerated social and technological change, the less flexible (for example elderly) segments of our societies are under heightened stress. Old life-worlds and value-systems are vanishing at such a pace, yesterday's skills are becoming useless so rapidly, one's knowledge about the world is getting updated so often that the feelings of disorientation, frustration and anxiety are almost inevitable, especially for the less flexible.

Adding this social issue to the wider context of Ove may seem somewhat farfetched for many who have seen the film, especially those who are moved by (and thus focused on) its sentimental journey into Ove's past. However, the old, grumpy man of the first scenes of the film, standing behind the locked entrance of his gated and fenced community, surrounded by signs of prohibition and warning, is already one of the most politically influential figures of our times [Fig. 6]. As we learn, it was Ove who invented most of these restrictions (where to drive, where to park cars, what kinds of pets are allowed, etc.), and it is also him who meticulously guards these rules, day after day, expressing direct anger and contempt for anybody who may break them. Thus, the film presents Ove as a guardian of a bygone age, an embittered defender of a fortification that he has turned his habitat into. The film establishes a clear allegorical relation between Ove and a previous, now vanishing Sweden, thus inviting the spectator to see the gated community as (Good Old) Sweden or (Fortress) Europe itself. The stereotypical characters of the film further emphasize this social (or national) allegory: apart from the old, grumpy man and white-shirt agents of the neoliberal capitalist order, there is a gay lad, an overweight lad, a Barbie-doll-like blond woman with high heels and a Chihuahua, an old couple with the husband paralysed, a well-meaning and socially engaged female journalist, and of course, the immigrants, that is, the newly arriving Persian-Swedish family. Ove's anxieties about what the world has come to are placed within this social tableau, and are clearly meant to be understood beyond the individual story, in more general or allegorical ways too.

Thus, A Man Called Ove also ventures to explore the psychological profile, or at least one such profile, of people who feel anxious and frightened of our rapidly transforming world, people who like to withdraw into their well-known smaller 
surroundings, who retreat into the local and the personal, who would very much like to turn back time. Today, when the world is still wrestling with the damaging, unforeseen side-effects of the Brexit referendum or Trump's presidency, it could be revealing to ask ourselves the following question (as a sort of thought experiment). If offered a referendum with which Ove could double-cross the white-shirts and could hope to turn back the processes of globalization and accelerated change, would he do it? Or: If such people as Ove, Joseph or Daniel saw a politician who promised them to make their country great again, punish the parasitical financial elites and their opportunistic white-collar servants, and bring back the good old days, would they vote for that politician? And if they did, should this come as a surprise?

The film paints a complex picture about the worth and chances of old men like Ove in such contemporary communities. First, it legitimizes Ove's grumpiness by telling the story of his losses. Second, it reveals that the principles that he upholds in such often annoying ways have much social value. Third, in a manner reminiscent of Joseph's defence of the young boy in Tyrannosaur, it suggests that this older generation of men were and are still capable of (even heroic) action. (Most notably, in a memory-scene we see Ove running into a burning house to save a child when nobody else dares to do anything.) And finally, the film suggests that with newly established, productive social relations these old men do have a chance of integrating into our changing societies (here it is mostly Ove's becoming friends with the Persian woman and eventually turning out to be a surrogate-grandfather to her children that serves the function of the essential social link).

In its approach to the above mentioned hot and no doubt pressing issues of early $21^{\text {st }}$-century Europe, A Man Called Ove applies an interesting and slightly deceiving strategy. By creating the allegorical association between Ove and Good Old Sweden, and by making the spectator more and more emotionally attached to his figure, the film also makes us feel nostalgic about the old Sweden that was transformed (or destroyed) by the globalized capitalism of the white-shirts. By this artistically successful but politically ambiguous strategy the film manages to tell a story about the loss of Good Old Sweden through a narrative of personal (and often romantic) loss. Mourning the death of Ove's father, wife, or Ove himself thus becomes a politically unproblematic way of mourning a past version of the nation or the local life-worlds lost in globalized capitalism. Likewise, the nostalgia evoked by the good old days seems less politically reactionary when it is associated with the memory of genuine, innocent, private happiness.

Through the absurd situation of telling a life story through the repeated suicide attempts of Ove, the film also comments allegorically on how difficult it is for this 
old kind of man to pass away. As many events unfold from his interrupted suicide attempts, in most of the present-day scenes Ove is wearing his "nice," blue, "tobe-buried-in" suit, which thus also serves as a constant reminder of his imminent passing from this world. As the narrative unfolds, this blue colour will gradually signify both the working class (blue-collar) and the feelings of mourning and melancholia. The connection of these two clusters of meaning through Ove's figure, who is working himself through situation after situation while secretly preparing for death, contributes to the film's commentary of the demise of the traditional working class and its iconic masculinities. Thus, A Man Called Ove is simultaneously an obituary, a farewell, an act of reckoning with the past, and a message to the future, on both personal and social levels.

Like Daniel Blake, there is a number of things Ove has to do before he dies. He has to fix things, such as punctured bicycles, leaking heating systems, broken relationships, and unchallenged aspects of his own self. The film suggests that these old men still have a lot to do, a lot to fix, a lot to add to the new world, which they do not recognize as their own, before they leave. Moreover, he also has to pass on things: objects, knowledge, skills and useful traditions. He gives the cradle he once made for their baby (who was never to be born) to the Persian-Swedish neighbours, explains how to park with a trailer, he teaches Parvaneh how to drive, and passes on his routines of checking the orderly functioning of the community to the younger generation. In the very last scene of the film, after Ove's funeral, it is the PersianSwedish little girl (Ove's foster-granddaughter) who turns back to properly lock the gate of the community, thus symbolically taking over Ove's responsibilities. Similarly to Tyrannosaur and I, Daniel Blake, the film sympathizes with some of the values of these old kinds of masculinities, and successfully demonstrates the social value of seemingly annoying or disturbing attitudes, personal characteristics. Yet, this acknowledgment of the values of (some of) the old ways of this old, white man does not seem to be shaped by any ideological masterplan or political doctrine, or at least not in overt ways: as the gate-checking scene suggests, maintaining (Ove's sense of) order in one's community is important, but it can be equally well done by unemployed overweight lads, gay kebab-makers or half-Persian schoolgirls.

Similarly to its message about orderliness, the film's criticism of global capitalism also lacks explicit political overtones. This is clearest in the episode when the community stands together to prevent a private caregiver company's taking away Rune, a paralysed elderly member, against the will of his wife, who wishes to keep taking care of him. Though the community demonstratively gathers in Rune's house to stop his forceful moving into the company's home (which, in Sweden, is paid 
by the government), what leads to success is the intervention of a female journalist from the local newspaper who manages to blackmail the white-shirts to back off by revealing the company's secret Channel Islands bank accounts and undeclared millions. Here the confrontation between global capitalism and the local community is physically manifest (the locals basically line up on the lawn), and the conflict between financial interests and human well-being, exploitation and solidarity is obvious. However, this does not translate as a nationalist or populist message: though the crooked "white-shirt scum" is driven out, and the gate is closed behind them, the community tableau is notably diverse, including young and old, Swedes and immigrants, blue-collar workers and educated people, straight and gay. It is in their standing together, overcoming their differences and the standard alienation of modern urban societies, it is their fight for what they value that makes Ove reintegrate into the community. It is no accidental detail, then, that Ove has his first heart attack only after this successful mission. Apparently, now, having passed on his fighting spirit, values and principles, he is more ready to go.

Though the above mentioned strategy to wrap national nostalgia in terms of personal or romantic mourning may suggest a conservative political stance legitimizing the attitudes of the older generation of white men, the film's ending rather resembles a liberal utopia. The way the community's internal differences are erased in their common fight against the white-shirts may call attention to the way difference is systematically underrepresented and downplayed in the film. Paravaneh, the Persian immigrant, for example, speaks perfect Swedish, dresses and behaves as a modern European woman, and shares more of Ove's principles than any other character. Her cultural difference is reduced to the fact that she puts saffron into rice meals (which Ove, actually, learns to appreciate). Similarly, the most damaging conflict that the community has seen, the one between Ove and Rune, stem from their loyalty to different car brands. While Ove is devoted to Saab, Rune always buys a Volvo, which distances them. The ultimate breaking point in their friendship is when Rune, after their children move abroad, decides to buy a BMW convertible, "the ultimate betrayal" - as Ove calls it. In these and other similar instances, there is nothing about differences of age, ethnicity, religion, political opinion or sexual orientation that could not easily be overcome. In a truly idealistic, even Hegelian manner, difference can be overcome and fully integrated into the system of the same. The film suggests that (except for the corrupted whiteshirt servants of global capitalism) all people are essentially good, they share the same values, their conflicts are easy to solve, mutual understanding and respect can be reached, and their living together is unproblematic. 


\section{Conclusions}

The most striking characteristic that these three films share in their depiction of old men is the association between crisis and ageing. Sometimes it is provoked by one's retirement, loss of employment, sometimes by the death of a spouse or close emotional support, but all three films are invariably crisis narratives. Though the stories of these crises are told through individual details, richly meaningful local settings, which clearly comment on the time, place and the specific social problems that these involve, all three male protagonists are allegorical figures, signifying (in various ways and degrees) the crisis faced by a whole generation of men, or a whole culture, life-world and ethos. Thus, following arthouse cinema's traditional approach of using old people as mirrors to the world, as critical perspectives on the life that they are leaving behind, all three films offer a critical analysis of contemporary European societies, and the lives lived in them.

One key aspect of the crisis these elderly white men are facing stems from their reduced social status and limited sense of agency. In case of Joseph and Daniel, this goes back mostly to financial and social reasons, such as living on benefits or losing even those benefits, being lonely, isolated, living outside the human and institutional systems of care. Accordingly, in these two British films the sense of crisis is depicted through evocative images of after-modern landscapes, run-down buildings, unheated and unfurnished apartments, closed-down shops and graffiticovered metallic shutters. In case of A Man Called Ove, the crisis lacks the financial aspect and the sense of a physically declining modern world, but the feeling of social and institutional malfunctioning is clearly there, as well as such other shared problems as isolation, loss of social and economic worth, the experience of redundancy, emotional vulnerability and humiliation. It is partly this more general or figurative sense of social commentary that makes death a key motif in all three films. Through the death of either the protagonist (I, Daniel Blake, A Man Called Ove) or a substitute close friend (in Tyrannosaur), the films comment on the passing of this older generation of men.

It is also quite significant that all three films express the idea that the world has changed and is no longer accommodating, comfortable or home-like for these men. They feel dispossessed, neglected and disregarded, they do not understand the new, "digital by default" world of globalized capitalism, run by the financial interests of international capital, faceless computers, difficult-to-operate softwares, and unfathomable algorhythms, as well as by an outsourced-by-default white-shirt bureaucracy that is clearly disconnected from the local people and the local issues 
they have to manage. This also affects the films' narrative trajectories, which are not driven by forward-looking desire, but by pain, mourning, melancholia, nostalgia and a wish to restore a life-world that has already been lost. This regressive, moribund journey is often presented as a destructive and self-destructive downwards spiral, which stems from one of the possible emotional responses that can be given to such situations of defeat, loss and disempowerment. Perhaps the fundamental emotional conflict of these films concerns precisely this inner struggle between progressive and regressive emotional responses. While the above listed painful and frustrating experiences drag these men down, towards more destructive and self-destructive journeys, we can also witness their desperate efforts to move forward, preserve the values that they cherish, reconnect with people, or to find new purpose for their lives. In this situation, another key issue is whether they can channel their frustration and anger in productive ways. The journeys of Joseph and Ove clearly run from more destructive to more productive uses of their bitterness and anger, however, Daniel's story is that of a series of frustrating attempts to keep up normalcy, and a resulting gradual falling down.

Importantly, social institutions fail in all three films: we can witness the crumbling of the great, innovative features of modern societies, most importantly the protective and care-giving function of the state (Porter 1999, 195-230). Thus, besides its personal stories, allegories of older kinds of masculinities, these films also dramatize the post-crisis shifts in the functioning of the state and the ensuing changes in the definition of citizenship. Many contemporary European citizens experience similar problems, the demise of the welfare state, the reduction of its caring functions, the outsourcing and privatization of health care, the malfunctions of bureaucracy, less secure streets and increased crime because of under-funded police departments, piles of garbage on the streets or unmaintained roads - these are all parts of post-crisis world and its after-modern landscapes. As the films also attest, such changes also undermine the post-war concept of the state as well as the late $20^{\text {th }}$-century idea of citizenship, and even forces the characters to go back to preindustrial human "networks of mutual aid" (Porter 1999, 195) or characteristically pre-modern systems of justice (killing the dangerous dog in Tyrannosaur, or blackmailing the private caregiving company in A Man Called Ove). One worrying aspect of this trend (on- and off-screen) is that these social systems of providing and care are probably not only the luxurious fruits of an affluent and politically stable form of modernity, but are also parts of its preconditions. When seeing the anger of either these old men in cinema or the millions of protest voters that come from the precariat, "the new dangerous class" (Standing 2011), it may be worth recalling that 
in the quickly industrializing German Reich of the 1880s, Bismarck introduced a system of welfare policies (which today we regard as the forerunner of the late $20^{\text {th }}$ century form of the welfare state) precisely as a means of defusing such anger and undermining proletariat-based revolutionary movements, which he recognized as a threat to the stability of the state (Porter 1999, 198).

Perhaps it is precisely this withdrawal or malfunctioning of the modern state that highlights the importance of individual action associated with these older forms of masculinity in these films, which often imply that the pre-crisis affluence and all-providing state created inert, passive, consumer-type citizens, who are simply not prepared for crisis-situations or the gradual withdrawal of the all-providing state. When in A Man Called Ove a man accidentally falls on the rails from the platform, most people simply watch without any idea what to do, and a woman even starts recording the scene with her phone. It is only Ove (who went there to jump in front of the train anyways) who jumps down, lifts the guy, and shouts at the onlookers to help him pull back the poor fellow to the platform. As several other situations in these films indicate, these older men were and perhaps still are capable of taking action in situations where there is no use waiting for some kind of public service to step in and solve the situation. His angry shouting at the onlookers can be interpreted as a symbolic wake-up call, forcefully dragging ordinary citizens (who are apparently not prepared for such a crisis) out of their slumber of passivity.

Such acts of help and solidarity, however, are not necessarily defined in these films as individual, heroic, or necessarily gendered masculine. These older men stand, rather, as catalysts, igniting social cohesion, action and a social dynamics of solidarity. In Tyrannosaur, it is the death of Joseph's old buddy that pulls the local community together, in I, Daniel Blake, it is Daniel's desperate street protest that brings ordinary pedestrians to some sort of political consciousness and united protest, and in A Man Called Ove, it is Rune's impending misery and Ove's angry intervention that makes the whole community stand up together against the greedy "white-shirt scum." Their anger, desperation, loud calls and spectacular deeds seem to be necessary for a proper social response to a crisis-situation, which response would include people, attitudes and styles of responses across divisions of race, class and gender. All three films refrain, however, from idealizing masculinity as the source of socially desirable action: on the contrary, all three films hint at the potentially destructive and/or self-destructive qualities of embittered old men, and imply that the individual frustration or anger of these men can be turned into socially productive, non-destructive action only with the support or guidance of female companions. 


\section{References}

Binstock, Robert H. and Linda K. George, eds. 2011. Handbook of Aging and the Social Sciences. Amsterdam: Academic Press.

Bradshaw, Peter. 2011. Tyrannosaur review. The Guardian, 6. October 2011. https:// www.theguardian.com/film/2011/oct/06/tyrannosaur-film-review. Last accessed 14. 12. 2019.

Certeau, Michel de. 1984. The Practice of Everyday Life. Berkeley: University of California Press.

Chivers, Sally. 2011. The Silvering Screen: Old Age and Disability in the Cinema. Toronto: University of Toronto Press.

European Commission. 2018. Ageing Report: Policy Challenges for Ageing Societies. https://ec.europa.eu/info/news/economy-finance/policy-implications-ageingexamined-new-report-2018-may-25_en. Last accessed 14. 12. 2019.

Frankenberg, Elizabeth and Duncan Thomas. 2011. Global Aging. In Handbook of Aging and the Social Sciences, eds. Robert H. Binstock and Linda K. George, 72-89. Amsterdam: Academic Press.

Friedman, Thomas. Thank You for Being Late: An Optimist's Guide to Thriving in the Age of Accelerations. New York: Farrar, Straus and Giroux.

Harrington Meyer, Madonna and Wendy M. Parker. 2011. Gender, Aging, and Social Policy. In Handbook of Aging and the Social Sciences, eds. Robert H. Binstock and Linda K. George, 323-335. Amsterdam: Academic Press.

Harwood, Jake and Karen Anderson. 2002. The Presence and Portrayal of Social Groups on Prime-time Television. Communication Reports vol. 15, no. 2: 81-97. Harwood, Jake. 2007. Understanding Communication and Aging: Developing Knowledge and Awareness. SAGE Online Publications.

Hattenstone, Simon. Ken Loach: 'If you are not angry, what kind of person are you?' Interview with Ken Loach. https://www.theguardian.com/film/2016/oct/15/kenlaoch-film-i-daniel-blake-kes-cathy-come-home-interview-simon-hattenstone. Last accessed 14. 12. 2019.

Kermode, Mark. 2016. I, Daniel Blake review - A Battle Cry for the Dispossessed. https://www.theguardian.com/film/2016/oct/23/i-daniel-blake-ken-loachreview-mark-kermode. Last accessed 14. 12. 2019.

Kohli, Martin and Camila Arza. 2011. The Political Economy of Pension Reform in Europe. In Handbook of Aging and the Social Sciences, eds. Robert H. Binstock and Linda K. George, 251-264. Amsterdam: Academic Press. 
Porter, Dorothy. 1999. Health, Civilization and the State. A History of Public Health from Ancient to Modern Times. London and New York: Routledge.

Woodward, Kathleen, ed. 1999. Figuring Age: Women, Bodies, Generations. Bloomington: Indiana University Press.

Woodward, Kathleen. 1991. Ageing and its Discontents: Freud and Other Fictions. Bloomington and Indianapolis: Indiana University Press.

\section{List of Figures}

Figure 1. Tyrannosaur (2011). Joseph sitting on the ruins of his torn-down shed.

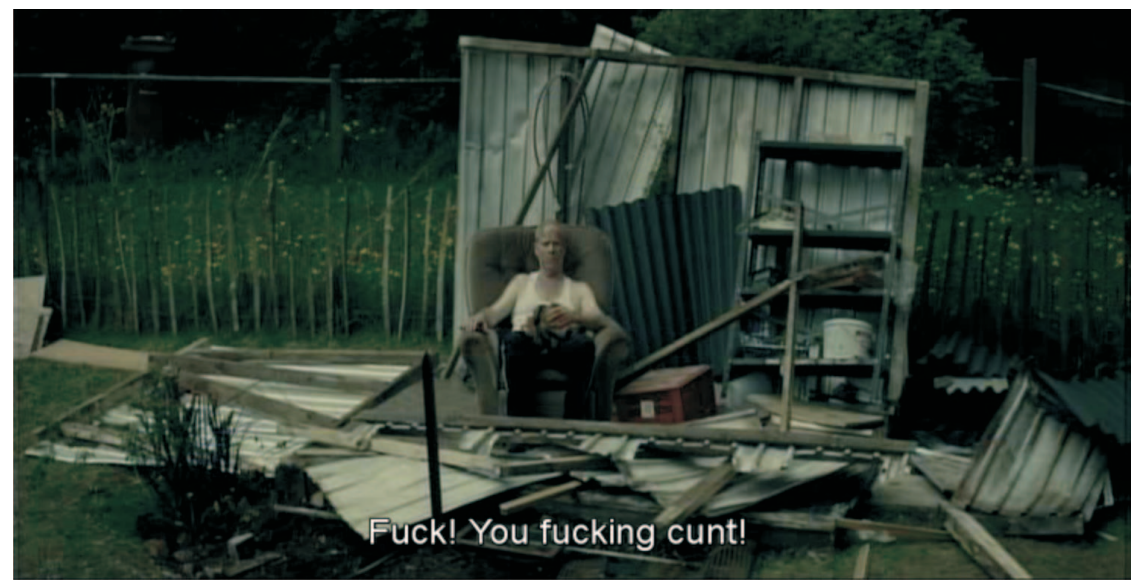

Figure 2. I, Daniel Blake (2016).

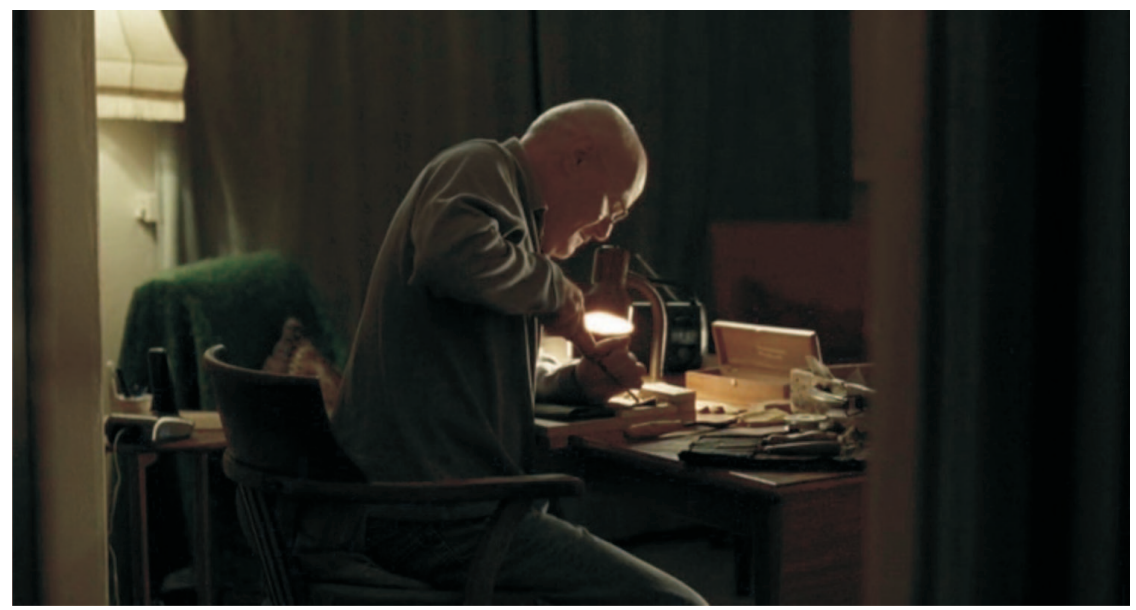


Figure 3. I, Daniel Blake (2016). Dan's graffiti: a human cry for justice and compassion in an increasingly inhuman world.

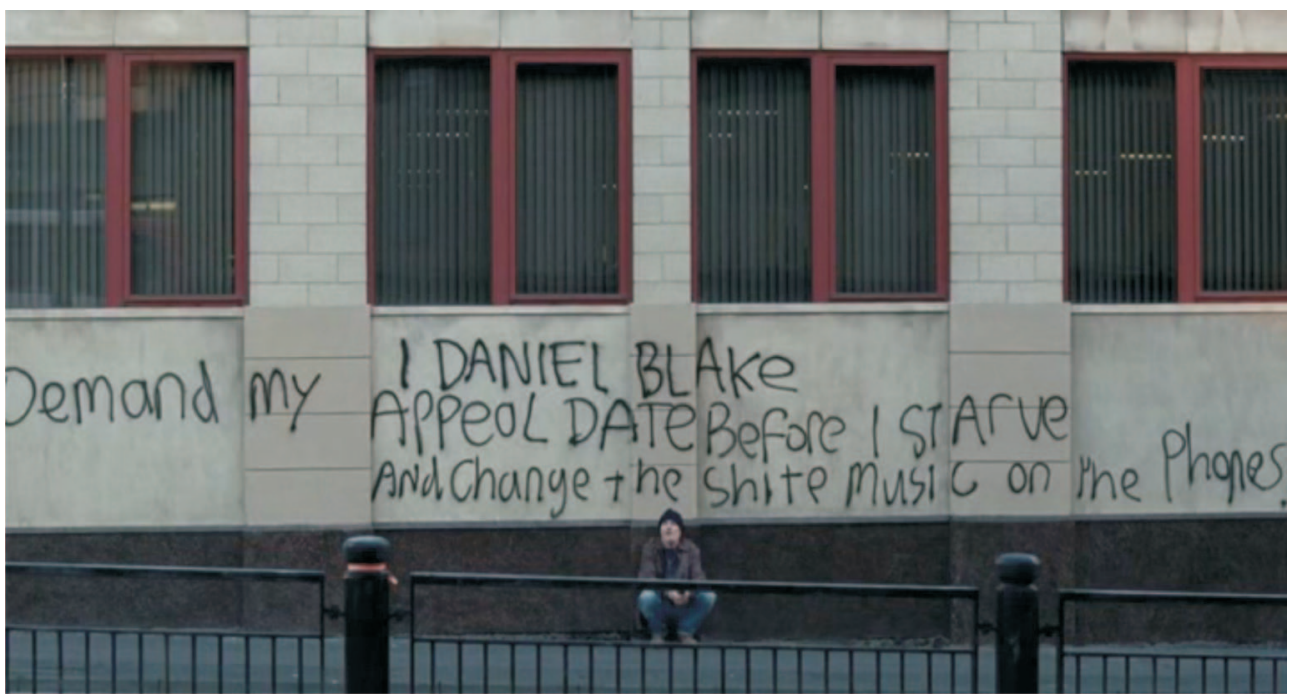

Figure 4. A Man Called Ove (2015). Ove in one of the highly symbolic compositions of the film: standing at the railway crossing, with his back to us, on his walk to the cemetery, visiting his wife's grave.

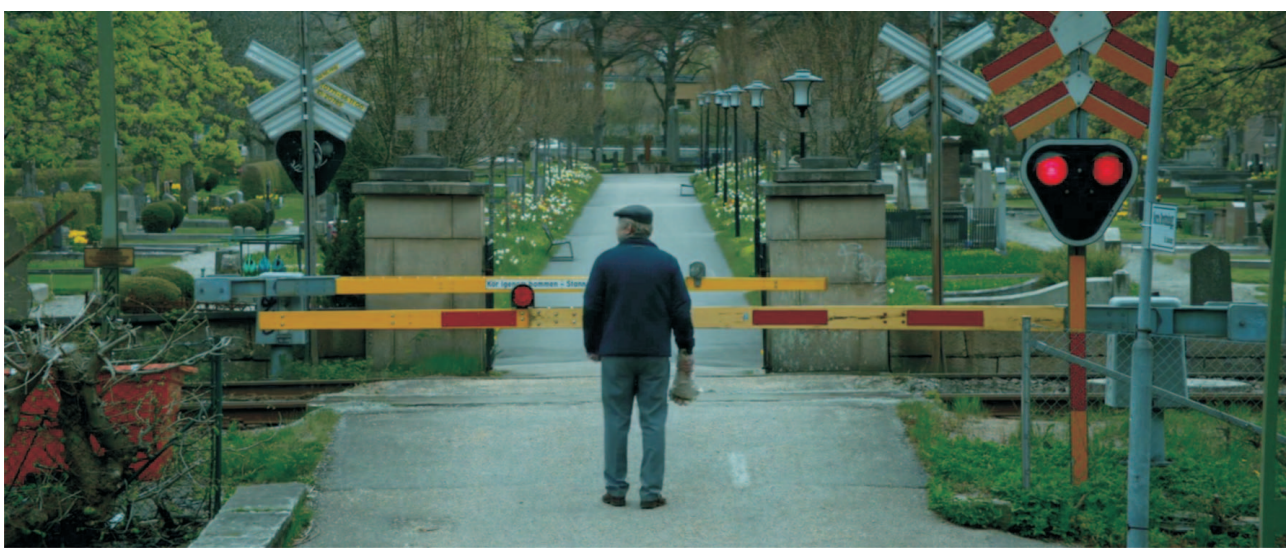

